\title{
Variability in Certainty of Self-Reported Interest: Implications for Theory and Research
}

\author{
Amanda M. Durik ${ }^{\text {a }}$ \& Jade S. Jenkins ${ }^{a}$ \\ ${ }^{a}$ Northern Illinois University, USA \\ Article received 15 May 2019 / revised 29 August / accepted 29 August / available online 30 March
}

\begin{abstract}
These studies examined self-reported interest, how level of interest is related to reported certainty of interest, and whether certainty helps to clarify the relationship between interest and behavior. This research borrows from research on attitudes showing that attitude certainty helps to clarify the relationship between attitudes and behavior. A pilot study examined the relationship between self-reported interest and certainty of interest within four disciplines (math, psychology, biology, and astronomy). These relationships were replicated in math (Study 1) and psychology (Study 2), and the relationships between interest and behavior were stronger for those with greater certainty. For domains in which participants had sufficient levels of experience and varied levels of interest, curvilinear relationships were found between level of interest and certainty, showing that certainty is higher among individuals who report more extreme (high or low) levels of interest. Moreover, self-reported interest predicted behavior more strongly for those with more certainty in their responses. Discussion surrounds the theoretical and methodological utility of considering certainty of interest alongside measures of self-reported interest.
\end{abstract}

Keywords: self-report; certainty; interest 


\section{Background}

When scanning a classroom, it is hard not to notice variability in student motivation. The students who are attentive, active, listening, and responding can be differentiated from those who are off task and distracted. Some of this differentiation can be traced to students' varying levels of interest in the domain that is being taught. Interest is an emotional response to particular stimuli that has both cognitive and motivational features (see reviews by Hidi \& Renninger, 2006; Krapp, 2002; Prenzel, 1992). It can guide students toward better self-regulation while learning because it helps students focus on content, choose to engage, persevere through challenges, and recall more. Interest is conceptualized as both residing in the person over time (individual interest) as well as varying in the moment in response to stimuli in the immediate situation (situational interest). As such, interest can fluctuate in response to processes operating within the person and stimuli present in the situation.

Individual interest is an enduring tendency to approach and seek learning opportunities in a given domain (Ainley \& Ainley, 2011; Deci, 1992; Hidi \& Renninger, 2006; Krapp, 2002; Prenzel, 1992; Renninger et al., 1992; Schiefele, 1991; Silvia, 2006). The domain is associated with affective involvement and meaningfulness (Schiefele, 1991), which are enhanced by the acquisition and use of knowledge (Hidi \& Renninger, 2006; Renninger, 2000; Prenzel, 1992). A hallmark of individual interest is willingness to reengage in the domain over time (Hidi \& Renninger, 2006).

The measurement of interest has been given considerable attention. Options of how to measure interest often include self-report scales and interviews (see discussions by Krapp \& Prenzel, 2011; Renninger \& Hidi, 2011). Within those, decisions about which features of interest should be captured vary. For example, within the collection of self-report scales that are available, some include feelings associated with interacting with domain content, the meaning or value associated with the domain, and/or the perceived knowledge or actual knowledge that individuals have stored in the domain (see review by Renninger \& Hidi, 2011).

Most conceptualizations of interest reflect the idea that interest can change in response to experience and exposure to content, and we argue that research on interest must inherently take a developmental perspective. This leads to challenges in measurement because any measure is a snapshot of a person's interest at a particular moment. Moreover, in the case of closed-ended self-report measures of interest, a given response is that person's best attempt at quantifying their level of interest at that time.

These issues also manifest in the capacity (or lack of, in some cases) for self-report measures of interest to predict behavioral manifestations of interest. Behavioral measures of interest often assess whether and how people choose to engage with domain content. Not surprisingly, measures of self-reported interest often positively predict behavior, such as free-choice behaviors observed in the laboratory, course taking, retrospective reports of behavior, and intentions to behave in the future (Ainley, Hidi, \& Berndoff, 2002; Harackiewicz et al., 2008; Renninger, 1990; Simpkins et al., 2006; Wijnia et al., 2014). That said, although correlations between self-reported interest and behavior are often present, they may not be as strong as one might expect.

Other areas of research have carefully considered why self-reported and behavioral data are not always strongly associated, and social psychologists who study attitudes began working on this issue within their own area in the 1970s. This work toward understanding the relationship between self-reported attitudes and behavior has led to greater clarity surrounding the nature of and research on attitudes. Similarly, careful attention to the relationship between self-reported interest and behavior may also help clarify the construct of interest. The challenges encountered by attitude researchers in assessing self-reported attitudes are likely similar to many of the challenges encountered by interest researchers assessing self-reported interest. In both cases, participants are asked to evaluate their responses to a particular class of stimuli or ideas. Although it is simple enough for an individual to provide a response on a scale, this deceivingly simple response is the outcome of much more complex processes.

It should be noted, however, that we do not argue that interest and attitudes are the same. Interest assumes an active process on the part of the individual that propels them toward knowledge acquisition, 
elaboration, or growth (Deci, 1992) whereas an attitude does not necessarily trigger this process and may actually do the opposite. For example, a person who holds a positive attitude toward recycling would believe that recycling is good. A person who holds a negative attitude about recycling would believe that recycling is bad, possibly a waste. Whereas the person with a positive attitude may be more open to learning about recycling than the person with a negative attitude, the attitude itself does not motivate learning. In contrast, a person with an interest in recycling would be expected to have learning goals related to recycling (e.g., a desire to learn about the processes related to recycling, which materials can be recycled, and why they should be recycled).

Attitude researchers have addressed the issue of attitude-behavior consistency in several ways. For example, one approach recognized that other environmental variables such as norms and the opportunity and ability to engage in the behavior were also critical (Ajzen, 1991). Another approach recognized that attitudes predicted behavior more strongly when people focused on only one side of an attitude (e.g., for or against; Glasman \& Albarracin, 2006). Finally, another approach identified that other attitude features contributed to attitude strength, and increased the relationship between attitudes and behavior (Krosnick \& Petty, 1995).

Borrowing from this last approach, the current research centers on the idea that individuals vary in the extent to which they are certain of their attitudes. Certainty refers to the extent to which individuals are confident in their assessment of an attitude as clear and correct (Rucker et al., 2014). Certain attitudes are held more strongly and are less likely to change (Krosnick \& Petty, 1995; Pomerantz et al., 1995). Moreover, participants who reported greater certainty of their attitudes, which was measured separately from the attitudes themselves, were more likely to behave in ways that were consistent with their attitudes (e.g., Bizer et al., 2006; Fazio \& Zanna, 1978; Glasman \& Albarraciin, 2006; Tormala, 2016; Tormala \& Rucker, 2007). As an example, although participants may report varying levels of attitudes toward recycling, those who have more certain and positive attitudes toward recycling would be more likely to actually recycle.

Just as individuals can report less or more certainty of their attitudes, we theorized that some participants would be more certain of their self-reported interest and others less so. We reasoned that if attitude researchers were able to clarify the relationship between attitudes and behaviors by considering attitude certainty, it was worthwhile to attempt the same for individual interest.

This approach, compared to some of the other approaches explored within the attitude literature, was selected because it preserved the assumption that research on interest must consider development. Interest changes and people may become more certain of their interest over time. As such, not only might the inclusion of certainty clarify the relationship between interest and behavior, but it may also provide insight into how participants' awareness of interest changes.

Specifically, certainty of interest may prove useful in gaining insight into the nature of interest and how individuals come to recognize their interests. Drawing again from the attitude literature, the extent to which individuals become more confident or certain of their attitude is related to the extent and valence of prior experiences and the amount of careful thought put toward the object of the attitude (Berger, 1992; Bizer et al., 2006; Fazio \& Zanna, 1978; Glasman \& Albarracin, 2006; Jonas et al., 1997; Krishnan \& Smith, 1998; Prislin et al., 1998). Prior experience and careful thought toward the object of an attitude have been found to increase certainty, which then contributes to stability of attitudes. The current research examines variability in certainty as a starting point in determining whether similar processes may be operating for interest as they are for attitudes.

The first aim of the current research is to examine certainty of interest and how certainty varies with levels of self-reported interest. The second aim was to test whether individuals who are more certain behave in ways that align more closely to their interests. 


\section{Pilot Study}

The purpose of the pilot study was to explore the patterns of association between self-reported interest and certainty of interest among different domains (math, biology, astronomy, and psychology). These domains were chosen because it was expected that participants would vary in their prior experience with each. The pilot sample was composed entirely of advanced psychology students. As such, this population was anticipated to have varying levels of exposure to math and biology (due to compulsory education), high exposure to psychology (as their program of study), and low exposure to astronomy (neither compulsory nor inherently linked to their program of study). This anticipated variability in experience with the different domains may have implications for certainty, and create meaningful comparisons across the domains.

We tested whether certainty and interest would be related in a linear or curvilinear fashion, and were especially interested in a curvilinear relationship such that participants who reported more extreme levels of interest (either low or high) may also be more certain of their interest. This pattern was found in prior research on attitudes revealing a curvilinear relationship between certainty and willingness to advocate for an attitudinal position (Cheatham \& Tormala, 2017). Moreover, if the relationship was linear, the redundancy in interest and certainty may undermine the utility of considering certainty of interest as separate from interest.

\subsection{Method}

Design

This was a correlational study using a within-participants design in which participants answered questions about their interest and certainty of interest in four domains.

\subsubsection{Participants}

The participants were 21 undergraduate students at a mid-sized university in the Midwestern United States. They were all in an upper-level psychology course that students typically complete their last year of undergraduate study. They completed the questionnaire in exchange for extra credit.

\subsubsection{Measures and procedure}

Participants responded to a 4-page, paper-and-pencil survey, in which questions for each domain (math, biology, astronomy, and psychology) were presented on different pages. The order in which participants responded about the different domains was counterbalanced across participants.

Participants responded to items assessing interest, certainty, and the number of college courses they had completed in the domain as well as other items that are not central to the current research. Interest was measured with 6 items that were adapted from those used in prior research and capture both feeling and meaning/value aspects of interest (Durik \& Harackiewicz, 2007). The scale included "I find _ interesting," "_ is fascinating to me," "I find _enjoyable," “_ is a boring subject," "_ just doesn't appeal to me," and "I think _ is a meaningful discipline." wherein the blank spaces were replaced with the domain name. Participants rated each item from 1 (Strongly disagree) to 7 (Strongly agree). Cronbach alphas for interest were .94 (math), .90 (biology), .77 (psychology), and .81 (astronomy). The lower reliability observed for psychology is likely due to restriction of range because all participants were highly interested in psychology, which is known to constrain estimates of reliability (Nunnally \& Bernstein, 1994).

Certainty was assessed with one item, "How sure are you of your attitudes about __?" and rated from 1 (Not at all) to 5 (Very much). Although only a single item was used, a similar approach has been taken in prior research (Gross et al., 1995). Participants were also asked, "How many college courses have you taken in __?" with response options ranging from zero to greater than eleven. This item was included in order to examine whether certainty was related to participants' prior exposure to the domain. 


\subsection{Results and discussion}

The data for this study (and both subsequent studies) were analyzed using multiple regression analysis conducted in SPSS Version 25.0. For each domain, certainty was designated as the criterion variable. The measure of interest in each domain was standardized and a squared term was calculated by multiplying the standardized measure by itself. These two variables, the standardized measure of interest and its square, were entered into the regression simultaneously to predict certainty of interest for that domain. For each effect, squared semi-partial correlations are provided as measures of effect size. These denote the portion of total variability in the outcome variable that is uniquely accounted for by a given predictor.

\subsubsection{Math}

The analysis predicting certainty of math interest revealed a negative average relationship of interest, $t(18)=-2.48, p=.02, B=-0.42, s r^{2}=.23$, and a positive quadratic relationship, $t(18)=2.54, p=.02, B=0.38$, $s r^{2}=.24$. The top left panel of Figure 1 depicts the relationship, showing that certainty was higher for those reporting either low or high levels of interest, and lower for those reporting more moderate levels of interest.

\subsubsection{Biology}

The analysis predicting certainty of biology interest revealed no relationship of interest, $t(18)=0.68$, $p=.51, B=0.12, s r^{2}=.02$, but similar to math, yielded a positive quadratic relationship, $t(18)=3.12, p<.01$, $B=0.65, s r^{2}=.35$. The bottom left panel of Figure 1 depicts the relationship. Similar to what was observed in math, participants who reported lower or higher levels of interest in biology also reported greater certainty, compared with those who reported more moderate levels of interest.

\subsubsection{Astronomy}

The model used to predict certainty of astronomy interest revealed a different pattern. Neither a linear relationship, $t(18)=0.68, p=.50, B=0.10, s r^{2}=.02$, nor a quadratic relationship, $t(18)=-0.18, p=.86, B=$ $-0.02, s r^{2}<.01$, emerged (see top right panel of Figure 1).

\subsubsection{Psychology}

The regression predicting certainty of psychology interest yielded a positive linear relationship of interest, $t(18)=3.34, p<.01, B=0.24, s r^{2}=.12$, as well as a negative quadratic relationship, $t(18)=-2.56, p$ $=.02, B=-0.19, s r^{2}=.07$. The bottom right panel of Figure 1 reveals a different quadratic relationship than was observed for math and biology. Among this sample of upper-level psychology students, interest appears to be positively related to certainty, and then levels off at the highest levels of interest and certainty. 

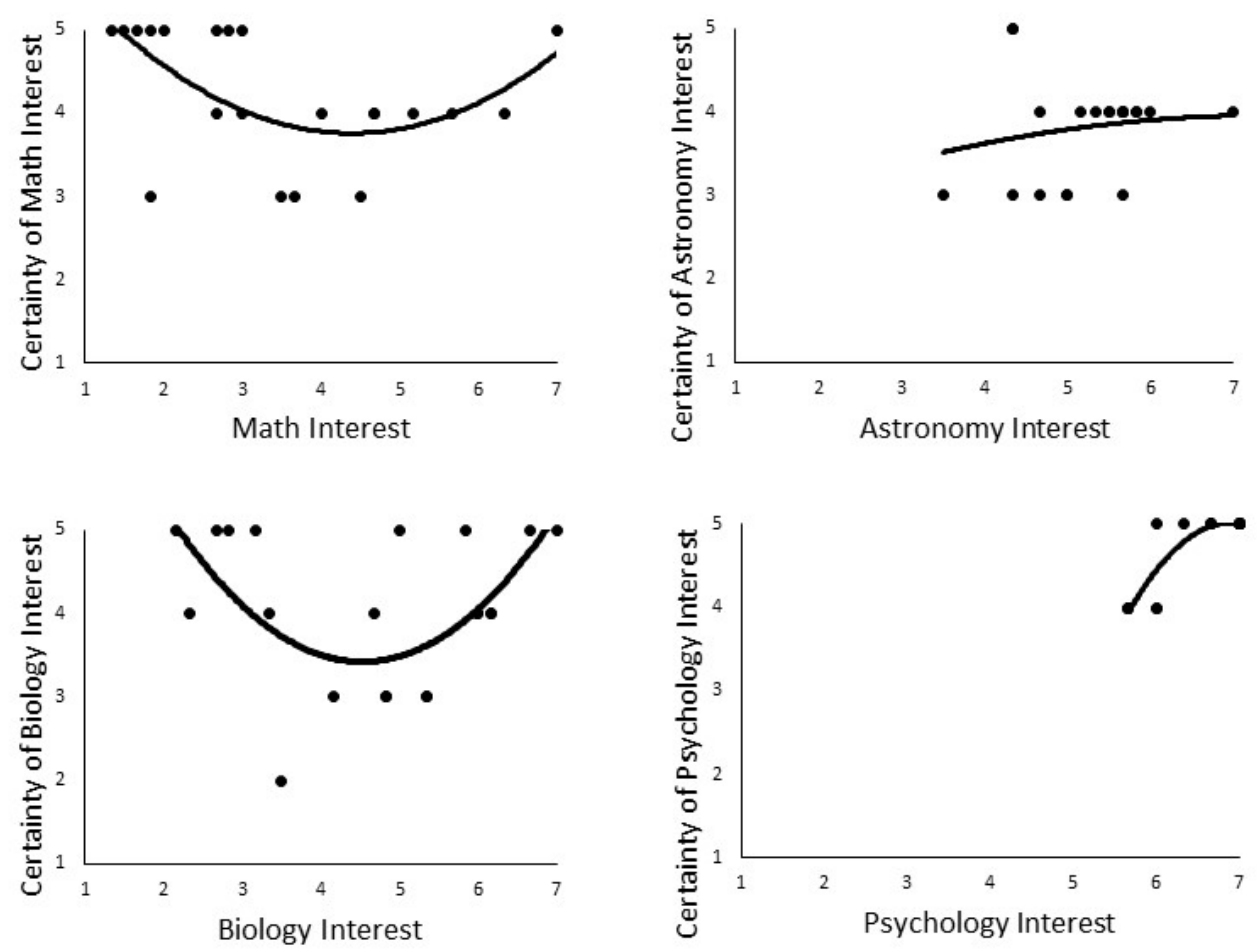

Figure 1. Curvilinear relationships tested between interest and certainty for each domain in the Pilot Study. Math and biology (left panels) revealed statistically significant $(p<.05)$ positive quadratic relationships, psychology (bottom right) revealed a significant negative quadratic relationship, and astronomy revealed no relationship (top right).

Overall these analyses of the relationships among level of interest and certainty reveals several things. First, the relationship between interest and certainty varies considerably by domain, such that negative quadratic relationships are observed in this sample for math and biology, a positive quadratic relationship was observed in this sample for psychology, and no relationship was observed for astronomy. These varied relationships are likely due to both the amount of experience these participants have with each domain, as well as their high interest in psychology due to the fact that participants were sampled from an upper-level psychology class. It seems likely that the quadratic relationships observed in math and biology are representative of most domains in which individuals have sufficient exposure to the domain to report their interest, and assuming that the sample includes the full range of interest. In most cases when participants are asked to report their interest, they have sufficient experience from which to draw conclusions about and be aware of their level of interest (either high or low) in the domain. In contrast, we interpreted the absence of relationships found in the astronomy domain as likely due to participants having had little prior exposure to astronomy. Lack of experience likely limited both their level of certainty as well as their extremity of interest in the domain. Finally, the results for psychology revealed a different quadratic pattern from the other three and reflects this sample's high certainty and high interest in psychology.

To examine whether certainty did covary with participants' prior experience, a final analysis was performed in which reports of certainty and the number of college courses reported was aggregated across participants. A correlation was calculated between the average number of courses students reported for each domain and the average level of certainty for each of the four domains. The correlation of the aggregated measures revealed a strong and positive association, $r(2)=.99, p<.01$, suggesting that the number of reported courses among participants in this sample was strongly and positively associated with level of certainty. One 
could imagine that a more thorough measure of prior experience, including courses taken in secondary school or informal learning opportunities, would add further insight into this relationship.

Although the sample size for this pilot study was extremely small and only included participants who were highly interested in psychology, the results were promising enough to explore further. Studies 1 and 2 were designed to examine these relationships more in depth within two domains, math and psychology, among participants drawn from a more general population.

\section{Study 1}

Study 1 was designed to replicate the results observed in the pilot study in the domain of math. Given that certainty of interest is likely to increase as individuals have more exposure to domains, and that students are exposed to years of compulsory math in primary and secondary school, we expected the negative quadratic relationship between interest and certainty that was observed in the pilot study to also emerge in Study 1 . The second purpose of Study 1 was to test the relationship between self-reported interest and behavior for those with lower or higher certainty. We hypothesized that self-reported interest in the domain would predict behavior in the domain positively and more strongly if individuals were more versus less certain of their interest.

\subsection{Method}

\subsubsection{Design}

This was a correlational study that took place in a laboratory context. Participants' math interest, certainty of math interest, and math-related behaviors were assessed in a single session.

\subsubsection{Participants}

The participants were 138 undergraduate students (54\% women) completing an introductory psychology course at a mid-sized university in the Midwest United States. They participated in the study for partial course credit. The sample included participants who reported their race or ethnicity as African American (24\%), Hispanic (16\%), Asian (9\%), Caucasian (48\%), or as another, unlisted category (3\%).

\subsubsection{Measures and procedure}

Participants were invited into the lab individually and completed the measures using MediaLab software (Jarvis, 2004). First, participants reported their interest in math using five items adapted from prior research (Harackiewicz et al. 2008), including "I've always been fascinated by mathematics," "I'm really excited about learning mathematics," "I'm really looking forward to learning more about mathematics," "I think mathematics is an important discipline," and "I think mathematics is important for me to know." Participants responded to each item from 1 (Strongly disagree) to 7 (Strongly agree). The internal consistency of the scale items was strong (Cronbach's alpha $=.90$ ).

Participants responded to 6 items designed to assess their certainty of interest (Krosnick et al., 1993). These items were, "How CERTAIN are you of your feelings toward mathematics?", "How SURE are you that your opinion of mathematics is correct?", "How FIRM are your opinions of mathematics?", "How EASILY could your opinion of mathematics be changed?" (reversed), "How DEFINITE are your views of mathematics?", and "How CONVINCED are you of your views of mathematics?" from 1 (Not at all__ to 7 (Very __ ), in which the blank restated the word in the question that was presented in capital letters. The reversed item was omitted because it decreased the internal consistency of the scale, which left 5 items (final Cronbach's alpha $=.91)$. 
Participants also had the opportunity to report their engagement in math-related behaviors. Behavioral indicators are often influenced by many factors in a given situation so the three behavioral indicators were combined into a composite after being standardized. One set of items asked participants to reflect on the past two years and indicate whether or not they had voluntarily chosen to engage in 12 activities related to math, including "I have surfed a website about mathematics in my spare time," "I have voluntarily discussed topics related to mathematics with friends or family," "I have chosen to join a club related to mathematics," and "I have spent free time reading a magazine article about mathematics." The number of behaviors indicated were summed for each participant.

Two additional behavioral measures occurred during the session. Participants were given a set of 10 math-related topics (e.g., "polygons and figures," "pi," "statistics," "quadratic equations") and asked to mark any about which they would like to receive more information via email (and to provide their contact information to do so). Participants were also given the opportunity to watch any of 5 short video clips about math-related topics (e.g., pi, mental math techniques, square roots). The number of topics marked and the number of videos watched were summed and each served as an additional measure of behavior. The standardized scores for all three measures were averaged to obtain the behavior composite (Cronbach's alpha $=.69$ ).

\subsection{Results and Discussion}

An exploratory factor analysis using oblique rotation was conducted to explore whether the measure of certainty was different from that of interest. Two eigenvalues over 1 emerged and the pattern matrix showed two factors with fairly simple structure. Each item had a loading of at least .74 on its expected factor and no loading over .07 on the unexpected factor.

The next analysis focused on testing the relationship between level of interest in math and certainty of math interest. As was done in the pilot study, this was achieved by conducting a multiple regression analysis in which certainty served as the criterion variable, and a standardized measure of interest as well as its square served as the two predictors. This analysis revealed both a positive relationship of interest, $t(135)=4.68, p<$ $.01, B=0.38, s r^{2}=.12$. as well as a positive quadratic relationship, $t(135)=6.02, p<.01, B=0.47, s r^{2}=.20$. Comparable to the pattern that emerged in the pilot study with regard to math, those with either lower or higher levels of interest in math also reported more certainty. In contrast, those who reported a moderate amount of interest in math reported lower certainty (see Figure 2). 


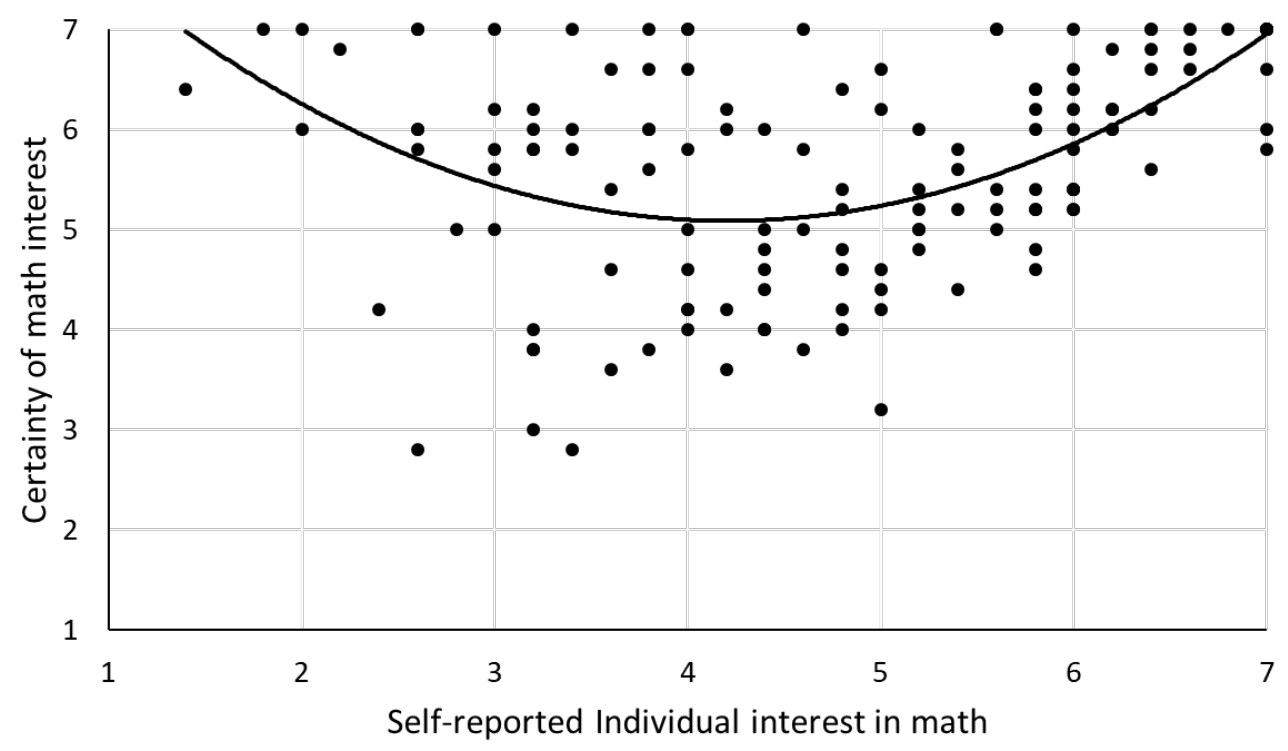

Figure 2. Curvilinear relationship observed between interest in math and certainty in Study 1.

The second analysis focused on whether the relationship between math interest and behavior would be positive and stronger for participants who reported greater certainty. To this end, a second regression analysis was conducted. The criterion variable was the composite measure of behavior and the three predictors included standardized measures of math interest, certainty of math interest, and their product. The analysis yielded a strong positive relationship of interest, $t(134)=4.67, p<.01, B=0.32, s r^{2}=.12$, and the predicted interaction, $t(134)=2.57, p=.01, B=0.17, s r^{2}=.04$, indicating that the relationship between interest and behavior varied depending on level of certainty. Certainty was not a significant predictor. Simple slope analyses were conducted to examine the relationship between interest and behavior separately for participants reporting certainty that was one standard deviation above and below the mean. The relationship between math interest and behavior was significant and positive for those with high certainty, $t(134)=7.12, p<.01, B=$ 0.49 , but not significant for those with low certainty, $t(134)=1.28, p=.20, B=0.15$ (see Figure 3 ).

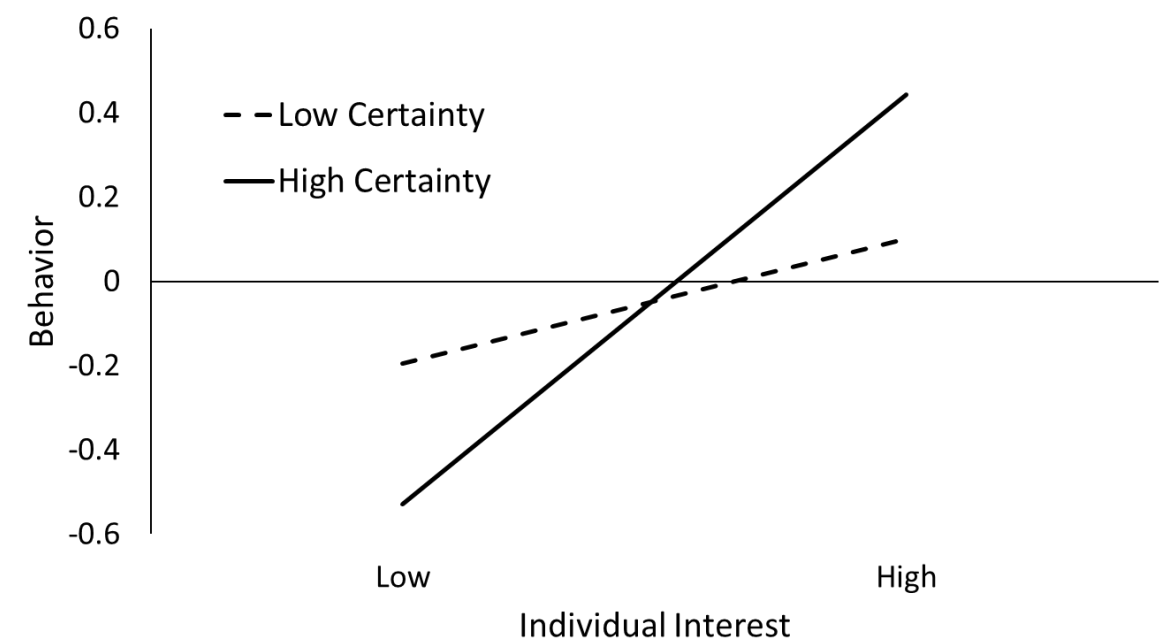


Figure 3. Interaction depicting different relationships between math interest and behavior for those reporting lower (one $S D$ below the mean) and higher (one $S D$ above the mean) certainty in Study 1.

These data replicate the pattern observed in the pilot study between math interest and certainty, and also showed that individuals who are more certain of their interest are more likely to behave in ways that are consistent with their levels of interest. In other words, those who are more certain of having lower interest are less likely to engage whereas those who are more certain of having higher interest are especially likely to engage. An interesting picture begins to emerge with regard to participants who are less certain. What is learned from Study 1 is that these participants' behavior is not as closely associated with their interest.

\section{Study 2}

Study 1 offered additional evidence that individuals' self-reported interest and certainty vary in a curvilinear way, and that participants with higher certainty are more likely to behave in ways that are consistent with their level of reported interest. Study 2 was designed to test this again but in a different domain, psychology. Psychology was chosen for two reasons. First, the pilot study showed that interest in psychology and certainty showed a different relationship (a negative quadratic relationship) in contrast to the positive quadratic relationship observed in Study 1 as well as the two other domains examined in the pilot study. We suspected that the observed relationship between interest and certainty for psychology found in the pilot study was due to the sample being composed entirely of highly interested psychology students nearing the completion of their degree. That said, it could instead be due to the domain itself. We wanted to examine the relationship between interest and certainty in psychology, but with a more general sample.

Second, psychology offered the possibility of testing the ideas related to interest and certainty with regard to individual interest as well as situational interest, given that the students were completing introductory psychology at the time that the data were collected. Whereas individual interest is thought of as an enduring person characteristic, situational interest refers to interest that is triggered by cues in the environment (Hidi \& Renninger, 2006; Mitchell, 1993; Schraw \& Lehman, 2001). Although individual interest and situational interest are often highly correlated, we reasoned that certainty may function differently for these two types of interest. Among students enrolled in an introductory psychology class, it was possible to examine overall individual interest in psychology as well as situational interest in the class, and compare how each measure of interest predicted behavior when taking into account level of certainty. We did not make hypotheses about whether one measure of interest (individual or situational) would predict behavior more strongly than the other.

\subsection{Method}

\subsubsection{Design}

This was a correlational study in which participants' interest in psychology, certainty of their interest, and behaviors related to the domain of psychology were assessed.

\subsubsection{Participants}

The participants included 142 undergraduate students (55\% women) completing an introductory psychology course at a mid-sized university in the Midwest United States. They participated in the study for partial course credit. Participants in the sample reported their race or ethnicity as African American (20\%), Hispanic (10\%), both African American and Hispanic (1\%), Asian (3\%), Caucasian (65\%), or as another, unlisted category $(1 \%)$. One person did not respond to the question about race/ethnicity.

\subsubsection{Measures and procedure}

There were two measures of interest, both individual and situational. To report individual interest, participants rated whether "Psychology is..." "interesting," "stimulating," "boring" (reversed), "engaging," "meaningful," "worthless" (reversed), and "useful" from 1 (Not at all) to 7 (Very much; Schiefele, 1990). Situational interest was measured with eight items reflecting the students' level of interest in their introduction 
to psychology course (e.g., "What we are learning in psychology class this semester is fascinating to me" and "We are learning valuable things in psychology class this semester"; Linnenbrink-Garcia et al., 2010). Participants responded to each item on a scale from 1 (Strongly disagree) to 7 (Strongly agree). The Cronbach's alphas for individual and situational interest were .88 and .95 , respectively.

Participants reported their certainty immediately following both measures of interest. The items that measured certainty were the same as in Study 1 and were general in that they did not specify whether participants should report certainty of individual or situational interest. Cronbach's alpha for the certainty measure was .88 .

At the end of the survey, reports of behavior were measured with two types of items, and the two types were standardized and combined into a composite in the same way as in Study 1. In parallel with Study 1, participants were asked whether or not they had engaged in 11 psychology-related behaviors in the past two years (e.g., "I have chosen to join a club related to psychology," "I have spent free time reading a magazine article about psychology"). Participants were also given the option of indicating whether they would like to receive information about various psychology-related topics, and if so, to mark their topic choices and provide their email address so this information could be sent. Fifteen topics were listed, designed to capture broad areas of psychology (e.g., "How the brain works," "Mental illness," "How memories form," and "Stereotyping and prejudice"). The total behaviors indicated and the total number of topics selected were both standardized and then averaged to form the composite measure of behavior. Given that there were only two types of behaviors, Cronbach's alpha for this measure was modest equaling .48, which may attenuate the relationships observed between interest and behavior. In contrast to Study 1, the option to offer participants videos to watch was not possible because Study 2 used pencil-and-paper surveys.

\subsection{Results and Discussion}

\subsubsection{Individual interest}

As in Study 1, an exploratory factor analysis was conducted on the certainty and interest items in order to evaluate their structure. The structure was not as clean as in Study 1, due to the two interest measures (individual and situational) having items that shared variability. This is not terribly surprising given the similarity in the constructs, methods of measurement, and timing. That said, the certainty items tended to load together and separately from the interest items, again attesting to the uniqueness of the certainty measure as a complement to typical measures of interest. We proceeded with the two separate measures of interest given their conceptual distinction but also recognize that the similarity in their measurement may hinder the ability to see predictive differences across the two measures.

As in Study 1, the first analysis was designed to test the relationship between level of interest and certainty, which was then followed by an analysis to test the relationship between self-reported interest and behavior, with the addition of certainty as a moderator.

A multiple regression model was tested using certainty of interest as the criterion variable, and interest and its square as the predictors. As in Study 1, the measures of interest were standardized prior to calculating the squared term. Replicating the relationship observed in Study 1 with the domain of math, individual interest in psychology had both a linear, $t(139)=5.68, p<.01, B=0.53, s r^{2}=.18$, and quadratic relationship with certainty, $t(139)=4.00, p<.01, B=0.22, s r^{2}=.09$. Similar to math, and unlike the relationship observed in the pilot study, certainty was higher for those with lower or higher interest in psychology, and lower for those who reported more moderate interest.

Next, to test whether interest was a stronger predictor of behavior for those with more certain interest, a multiple regression model was tested in which the behavior composite was the criterion variable and the three predictors were the standardized composite measure of individual interest, the standardized measure of certainty, and their product. This analyses revealed a positive relationship between interest and behavior, $t(138)$ $=5.09, p<.01, B=0.34, s r^{2}=.10$, as well as an interaction, $t(138)=1.99, p<.05, B=0.12, s r^{2}=.02$ (see 
Figure 4). Simple slope tests were conducted to examine the relationship between interest and behavior for those scoring one standard deviation below and above the mean of certainty. These analyses revealed that the relationship between individual interest and behavior was significant and positive for both, but stronger for those with higher certainty, $t(138)=6.04, p<.01, B=0.46$, than for those with lower certainty, $t(138)=2.17$, $p=.03, B=0.22$.

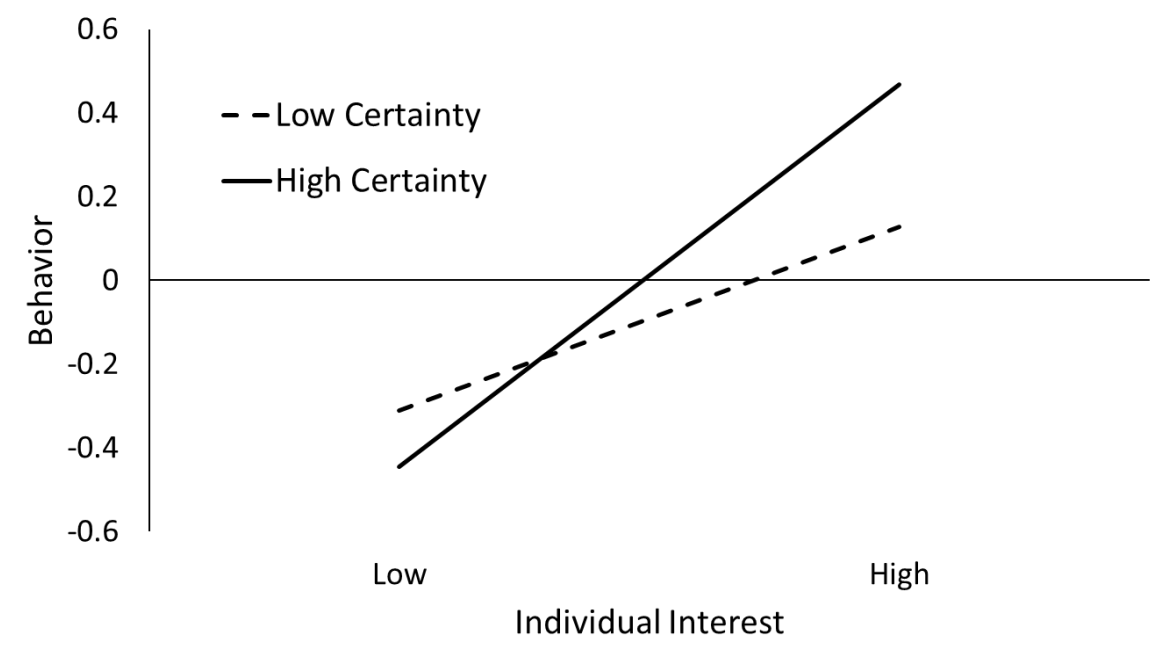

Figure 4. Interaction depicting different relationships between psychology interest and behavior for those reporting lower (one $S D$ below the mean) and higher (one $S D$ above the mean) certainty in Study 2.

These relationships replicate the patterns that were observed in Study 1. Furthermore, the pattern between interest in psychology and certainty that was observed in the pilot study seems to have been due to the sampling of participants for the pilot study and not to the domain.

\subsubsection{Situational interest}

The next set of analyses were parallel to those described for individual interest, but instead focused on situational interest.

When situational interest in the psychology class was used to predict certainty, both a linear relationship, $t(139)=5.48, p<.01, B=0.48, s r^{2}=.17$, and a quadratic relationship, $t(139)=3.17, p=.02, B$ $=0.21, s r^{2}=.06$, emerged. Participants who reported more extreme levels of situational interest also reported greater certainty whereas those who reported more moderate levels of situational interest reported less certainty.

When situational interest, certainty, and the interaction between them were used to predict the composite measure of behavior, both situational interest, $t(138)=2.71, p<.01, B=0.19, s r^{2}=.05$, and their interaction were significant, $t(138)=2.29, p=.02, B=0.15, s r^{2}=.03$. Simple slopes were tested and showed that situational interest positively predicted behavior for those with higher certainty, $t(138)=4.10, p<.01, B$ $=0.34$, but did not predict behavior for those with lower certainty, $t(138)=0.40, p=.69, B=0.04$.

The results from both individual and situational interest demonstrate that certainty may be useful in better predicting behavior with both types of interest. If anything, the interaction was slightly more pronounced for situational than for individual interest, although this difference was not tested directly. One explanation is that the salience of an ongoing situation may be a vivid motivator of behavior toward (or away from) domain content. However, this pattern is also tied to the nature of the situation assessed here. Given that the situation that defined situational interest in this study was in reference to a semester-long, introductory class, situational interest as well as the behavior were in reference to a fairly broad definition of the field in general. Other 
situations that are more narrow (e.g., focused on a particular topic) may not predict behavior as strongly, especially if the behavioral opportunity is more broad or more narrow than the experience of situational interest.

\section{General Discussion}

This research lays out some of the complexity inherent in asking individuals to self-report their interest and recognizes that these self-reports may be more or less certain. For domains in which individuals have varied amounts of experiences and sufficient prior exposure (e.g., math, psychology, and biology), there appears to be a curvilinear relationship between self-reported interest and self-reported certainty. Individuals who reported more extreme levels of interest (either high or low) tended to report being more certain of their interest. In other words, when individuals were quite interested in a domain, they were sure of the presence of their interest; when individuals were quite disinterested in a domain, they were also sure of their lack of interest. Moreover, as predicted, level of interest was a stronger predictor of behavior when certainty was high than when certainty was low. It is not clear from these data whether participants who are less certain (and more moderate in their interest) have truly neutral beliefs about the domain or if they actually have both positive and negative experiences, which are best captured as neutral on this bidirectional scale.

\subsection{Promises and Pitfalls of Self-Report Measures}

Certainty of interest highlights both a promise and a pitfall of using self-report measures to assess interest. This research speaks to two of the three main questions guiding the compilation of this special issue. First, this research relates to the complexity of interpreting self-report data. On the one hand, if a sample has high certainty of their interest, then self-report measures may be easier to interpret. The certainty with which people report their interest may support processes that strengthen associations between interest and various behavioral outcomes.

In considering this promise, however, it is also critical to consider the pitfall; when people are not certain, they will still provide a response but that response may not be rooted in as much experience, which could make interpretation difficult. If participants are asked to provide reports of interest in domains in which they have little experience, their reports will be ill-informed. This challenge adds to the challenge of inattentiveness, examined by Iaconelli and Wolters (2020). The interpretation of self-report data will likely be murky not only when people are responding inattentively, but also when they are attentive but do not have sufficient self-knowledge or experience with which to provide a meaningful response.

Although the current work centers on the certainty with which individuals can identify their interests, certainty may extend to other types of reports as well, such as certainty in metacognition and strategy use. Other authors in this issue (e.g., Rogiers et al., 2020; van Halem et al., 2020), report how self-reported measures link to trace measures that occur during task engagement, and to subsequent behavior. These relationships may be stronger to the extent that participants are more certain of their self-reported meta-cognition and strategy use.

Second, this research also highlights constraints of self-report data that have implications for methodology. Self-reported domain interest may be less valid when interest is in early phases of development (e.g., Renninger \& Hidi, 2011), and this research suggests that certainty may capture an important element. It may take months and years for individuals to collect information about their response to a given domain in order to have certainty in their level of interest (either high or low). Presumably, the development of this certainty will emerge as individuals have experiences with a domain and then think back to them retrospectively (see Dinsmore et al., this issue for a discussion of retrospective processes). If interest must be measured among a sample with limited certainty of interest, one approach may be to provide supports for them 
to know how to respond (e.g., definitions of the domain, a particular experience to reflect on) in order to provide a more valid measure, or to assess interest multiple times during a task (Moeller et al., 2020) rather than relying on a global assessment of domain interest.

Alternatively, researchers may want to consider certainty when selecting domains to study and identifying appropriate samples within those domains. It is noteworthy that the sample in the pilot study had relatively little certainty about their interest in astronomy and very strong certainty about their interest in psychology. Given the results of Studies 1 and 2, this might also have implications for behavior. If the purpose of a research study is to use interest to predict behavior, then it may be wise to select a domain in which participants have considerable experience in the domain (i.e., math), because interest may predict behavior if the sample as a whole has more experience with the domain. That said, it is also important to have variability in the sample so that it represents the full range of interest, with which to predict behavior. The pilot study included a sample composed entirely of students in their last year of studying psychology. Although this sample reported very high certainty, restriction of range in their interest is likely to have limited any observed association between level of interest and behavior, had behavior been assessed.

\subsection{Implications for Theory}

The observed relationship between interest and certainty may be related to participants' experiences with domain content, and captures the changing aspect of interest within a developmental trajectory. Data from the pilot study showed that the number of classes students took in each domain positively predicted certainty in a linear fashion. Prior experience also varied along with the different observed relationships between interest and certainty across the domains. No reliable relationship was detected in the domain of astronomy, likely because participants had such limited experiences in the domain, and the opposite quadratic relationship was detected in the domain of psychology, presumably because students had extremely high interest and certainty. Although these fluctuations are consistent with research on attitudes showing that direct experience contributes to attitude certainty (see review by Glasman \& Albarracin, 2006), the nuances of how this occurs is important to consider for understanding how individuals come to recognize and be aware of their interest.

One possibility is that the extremity of the emotion prompts awareness of the experience and contributes to certainty. Individuals who have relatively intense experiences in a domain - experiences that are either highly interesting or highly distasteful - may come to realize their level of interest and have greater certainty (Dutta et al., 1972). In contrast, those who have more mixed or vague reactions may be less aware of their emotional reaction to the domain content, which then leaves them with less certainty of their interest.

Another possibility is that the clarity or vividness of individuals' memories contributes to certainty. For example, those who have had multiple, semester-long courses in the domain may have more vivid memories of learning in that domain, which may contribute to greater certainty. Along these lines, it may be fruitful to bring research on autobiographical memory into research on interest in order to better understand how individuals recall prior experiences that may inform their report of interest. Research suggests that the valence of how an event ends has a disproportionate influence on how the event is remembered (Kahneman et al., 1993). Research on interest may benefit by building on this foundation from the memory literature in order to better understand not only how interest develops, but whether the timing of experiences impacts how people recall the events that they come to see as foundational to their perception of interest in the domain.

\subsection{Implications for Research}

Certainty may also provide a handle for predicting whose interest may be more or less altered by new experiences with a domain. For example, individuals who are less certain of their interest may be more responsive to situational variables designed to affect interest. Less certain individuals may be more open to collecting information through their experiences with domain content and updating their level of interest. If so, situational enhancements designed to foster interest may be more effective for low versus high certain 
individuals. As such, it may be beneficial to assess certainty of interest in research testing interventions designed to foster interest. The effects of a situational intervention may be positive for a subset of individuals (i.e., those with lower certainty), but this effect may be masked by others who are more certain and therefore less likely to change their level of interest.

In a sense, if one thinks of situational interest as being analogous to attitudes in the face of persuasive attempts, then the attitudes literature provides some hints of this possibility as well. For example, Tormala (2016) has noted how curiosity is itself a form of "interested uncertainty" which, in some situations, can aid persuasion. Specifically, Kupor and Tormala (2015, Study 3) reason that curiosity motivates more thorough processing of the persuasive message and increases the message's impact. This may suggest that a similar process could explain differential impact of situational enhancements that are designed to foster interest. In general, future directions focused on underlying cognitive and affective processes are warranted and would very much help illuminate how interest may or may not change in response to new experiences.

\subsection{Differences Between Attitudes and Interest}

Although this research was initiated because of similarity between interest and attitudes, these constructs are not the same, which has implications for how they emerge and function. For example, certainty in the attitude literature has been divided into correctness and clarity (Petrocelli et al., 2007). Whereas correctness reflects the veraciousness of an attitude in an absolute sense (e.g., efforts to slow global warming is the correct perspective), clarity is the extent to which individuals are confident that they know their own stance (i.e., I know my attitude about efforts to slow global warming). Applied to interest, clarity is more relevant than correctness if one assumes a stance of relativism, in which interest in one domain is not more valuable or correct than interest in any other domain.

A difference between the attitude and interest literatures also emerges when one considers what is being evaluated when self-assessing an attitude versus self-assessing level of interest. Attitude objects are typically outside the person and the question is whether the person agrees with or disagrees with the attitude object. This is in contrast to interest in which the person assesses how they interact with the domain. When people evaluate their interest, they evaluate their personal experiences with it and how they respond to the domain. As such, assessments of an attitude object may be more about the object and less about how the person interacts with the object. For interest, in contrast, the assessment is about one's own response to the domain.

\subsection{Limitations}

Finally, although positive relationships between interest and behavior were observed in the domains of math and psychology, the direction of causality is not clear in the present correlational studies. The theoretical model describing the relationship between interest and behavior typically places interest as the motivation (i.e., cause) of behavior; however, it is also worth pointing out that behavior may influence selfreports of interest as well as certainty. Research on attitudes has addressed several of these processes (see review by Olson \& Stone, 2005). When individuals are unsure of their attitudes, they may reflect on their past behavior as information that can be used to inform their attitude (e.g., Bem, 1967). For example, when asked about global warming, individuals may scan their memories for events in which they chose to engage in proenvironment activities or not. These memories may lead them to decide on a particular self-reported attitude. A similar process may operate with regard to interest, especially when individuals have less certainty of their interest. For example, when participants in the pilot study were asked about their interest in astronomy, the domain in which they had taken the fewest classes, they may have tried to recall relevant memories. Those who could generate more positive memories are likely to have rated their interest higher than those who could generate fewer memories, or negative memories.

It is also worthwhile to consider how behaviors may affect self-reported interest ratings, which can also explain the observed relationships between interest and behavior found in this set of studies. In Studies 1 
and 2, participants first reported their interest, then their certainty of interest, and finally responded to behavioral opportunities. It is possible that participants felt pressure to behave in a way that was consistent with their initial reports, which may have strengthened the observed results (Olson \& Stone, 2005). Specifically, those who had just reported low or high levels of interest may have felt internal pressure to behave in ways that were consistent with their reports, and this may have been especially strong for those who reported greater certainty. The present research does not address this possibility, but opens up a line of research in which these ideas could be explored.

Finally, specific features of the studies reported here also warrant caution in drawing broad conclusions. The pilot study examined prior exposure to various domains by collecting information on students' course experiences. However, experiences in high school courses and extracurricular activities may have also provided opportunities for exposure. Inclusion of all these experiences could help paint a fuller picture of the relationship between domain exposure and certainty. Furthermore, these studies involve a very narrow sample of individuals - namely, undergraduate students at a single university who are taking a psychology course. For example, it is healthy to question whether similar patterns would be observed among a sample of older adults (e.g., who may have more experience and greater certainty) or younger children (i.e., who may have even less experience than the sample tested in the current research). Moreover, these psychology students may have been especially sensitive to environment cues or demand characteristics related to behaving in ways that are more consistent with their stated interest. This tendency would be exaggerated if participants felt that the desired response involved giving higher interest ratings and engaging in more behaviors. These questions cannot be answered with the current data but could be tested in the future.

\subsection{Concluding Thoughts}

In summary, when interest is self-reported, the report reflects a synthesis of what individuals have available to them at the moment of measurement, and these reports are more certain for some participants than for others. This variation in certainty may provide a lens for better understanding how interest develops and how it is internalized and becomes known to individuals. As with any type of measure, it is critical to interpret the data in light of the assumptions, capacities, limitations, and processes that are relevant at the time of measurement.

\section{Keypoints}

- Self-reported interest varies in certainty across individuals

- Those with greater certainty self-report more extreme interest (high or low)

- Self-reported interest and behaviour correlate more strongly for those with greater certaint 


\section{References}

Ainley, M., \& Ainley, J. (2011). A cultural perspective on the structure of student interest in science. International Journal of Science Education, 33, 51-71. https://doi.org/10.1080/09500693.2010.518640

Ainley, M., Hidi, S., \& Berndorff, D. (2002). Interest, learning, and the psychological processes that mediate their relationship. Journal of Educational Psychology, 94, 545-561. https://doi.org/10.1037//00220663.94.3.545

Ajzen, I. (1991). The Theory of Planned Behavior. Organizational Behavior and Human Decision Processes, 50, 179-211. https://doi.org/10.1016/0749-5978(91)90020-T

Bem, D. J. (1967). Self-perception: An alternative interpretation of cognitive dissonance phenomena. Psychological Review, 74, 183-200. https://doi.org/10.1037/h0024835

Berger, I. E. (1999). The influence of advertising frequency on attitude-behavior consistency: A memory based analysis. Journal of Social Behavior \& Personality, 14, 547-568.

Bizer, G. Y., Tormala, Z. L., Rucker, D. D., \& Petty, R. E. (2006). Memory-based versus on-line processing: Implications for attitude strength. Journal of Experimental Social Psychology, 42, 646-653. https://doi.org/10.1016/j.jesp.2005.09.002

Cheatham, L. B., \& Tormala, Z. L. (2017). The curvilinear relationship between attitude certainty and attitudinal advocacy. Personality and Social Psychology Bulletin, 43, 3-16. https://doi.org/10.1177/0146167216673349

Deci, E. L. (1992). The relation of interest to the motivation of behavior: A self-determination theory perspective. In K. A. Renninger, S. Hidi, \& A. Krapp, A. (Eds.), The role of interest in learning and development (pp. 43-70). Hillsdale, NJ: Lawrence Erlbaum.

Dutta, S., Kanungo, R. N; \& Freibergs, V. (1972). Retention of affective material: Effects of intensity of affect on retrieval. Journal of Personality and Social Psychology, 23, 6480. https://doi.org/10.1037/h0032790

Fazio, R. H., \& Zanna, M. P. (1978). Attitudinal qualities relating to the strength of the attitude- behavior relationship. Journal of Experimental Social Psychology, 14, 398-408. https://doi.org/10.1016/00221031(78)90035-5

Glasman, L. R., \& Albarracin, D. (2006). Forming attitudes that predict future behavior: A meta-analysis of the attitude-behavior relation. Psychological Bulletin, 132, 778-822. https://doi.org/10.1037/00332909.132.5.778

Gross, S. R., Holtz, R., \& Miller, N. (1995). Attitude certainty. In R. E. Petty \& J. A. Krosnick (Eds), Attitude strength: Antecedents and consequences (pp.215-245). Mahwah, NJ: Lawrence Erlbaum.

Harackiewicz, J. M., Durik, A. M., Barron, K. E., Linnenbrink-Garcia, L., \& Tauer, J. M. (2008). The role of achievement goals in the development of interest: Reciprocal relations between achievement goals, interest and performance. Journal of Educational Psychology, 100(1), 105-122. https://doi.org/10.1037/0022-0663.100.1.105

Hidi, S. \& Renninger, K.A. (2006). The four-phase model of interest development. Educational Psychologist, 41, 111-127. https://doi.org/10.1207/s15326985ep4102_4

Iaconelli, R. \& Wolters C.A. (2020). Insufficient Effort Responding in Surveys Assessing Self-Regulated Learning: Nuisance or Fatal Flaw? Frontline Learning Research. 8 (3) $104-125$. https://doi.org/10.14786/flr.v8i3.521

Jarvis, W. B. G. (2004). MediaLab [Computer software]. New York: Empirisoft.

Jonas, K., Diehl, M., \& Broemer, P. (1997). Effects of attitudinal ambivalence on information processing and attitude-intention consistency. Journal of Experimental Social Psychology, 33, 190-210. https://doi.org/10.1006/jesp.1996.1317 
Kahneman, D., Fredrickson, B. L., Schreiber, C. A., \& Redelmeier, D. A. (1993). When more pain is preferred to less: Adding a better end. Psychological Science. 4, 401-405. https://doi.org/10.1111/j.1467-9280.1993.tb00589.x

Krapp, A. (2002). An educational-psychological theory of interest and its relation to SDT. In. E. L. Deci \& R. M. Ryan (Eds.), Handbook of self-determination research (pp. 405-427). Rochester, NY: University of Rochester Press.

Krapp, A., \& Prenzel, M. (2011). Research on interest in science: Theories, methods, and findings. International Journal of Science Education, 33, 27-50. https://doi.org/10.1080/09500693.2010.518645

Krishnan, H. S., \& Smith, R. E. (1998). The relative endurance of attitudes, confidence and attitude-behavior consistency: The role of information source and delay. Journal of Consumer Psychology, 7, 273-298. https://doi.org/10.1207/s15327663jcp0703_03

Krosnick, J. A., Boninger, D. S., Chuang, Y. C., Berent, M. K., \& Carnot, C. G. (1993). Attitude strength: One construct or many related constructs? Journal of Personality and Social Psychology, 65, 11321151. https://doi.org/ 10.1037/0022-3514.65.6.1132

Krosnick, J. A., \& Petty, R. E. (1995). Attitude strength: An overview. In R. E. Petty \& J. A. Krosnick (Eds.), Attitude strength: Antecedents and consequences (pp. 1-24). Mahwah, NJ: Lawrence Erlbaum.

Kupor, D. M., \& Tormala, Z. L. (2015). Persuasion, interrupted: The effect of momentary interruptions on message processing and persuasion. Journal of Consumer Research, 42, 300-315. https://doi.org/ $10.1093 /$ jcr/ucv018

Linnenbrink-Garcia, L., Durik, A. M., Conley, A. M., Barron, K. E., Tauer, J. M., Karabenick, S. A., \& Harackiewicz, J. M. (2010). Measuring situational interest in academic domains. Educational and Psychological Measurement, 70, 647-671. https://doi.org/10.1177/0013164409355699

Mitchell, M. (1993). Situational interest: Its multifaceted structure in the secondary school mathematics classroom. Journal of Educational Psychology, 85, 424-436. https://doi.org/10.1037/00220663.85.3.424

Moeller, J., Viljaranta, J., Kracke, B., \& Dietrich, J. (2020). Disentangling objective characteristics of learning situations from subjective perceptions thereof, using an experience sampling method design. Frontline Learning Research. 8 (3) 63-84. https://doi.org/10.14786/flr.v8i3.529

Nunnally, J. C., \& Bernstein, I. A. (1994). Psychometric theory ( $3^{\text {rd }}$ ed.). New York: McGraw-Hill.

Olson, J. M., \& Stone, J. (2005). The influence of behavior on attitudes. In D. Albarracin, B. T. Johnson, \& M. P. Zanna (Eds.), The handbook of attitudes (pp. 223-271). Mahwah, NJ: Lawrence Erlbaum.

Petrocelli J. V., Tormala, Z. L., \& Rucker, D. D. (2007). Unpacking attitude certainty: Attitude clarity and attitude correctness. Journal of Personality and Social Psychology, 92, 30-41. https://doi.org/10.1037/0022-3514.92.1.30

Pomerantz, E. M., Chaiken, S., \& Tordesillas, R. S. (1995). Attitude strength and resistance processes. Journal of Personality and Social Psychology, 69, 408-419. https://doi.org/10.1037/00223514.69.3.408

Prislin, R., Wood, W., \& Pool, G. J. (1998). Structural consistency and the deduction of novel from existing attitudes. Journal of Experimental Social Psychology, 34, 66-89. https://doi.org/10.1006/jesp.1997.1343

Renninger, K. A. (1990). Children's play interests, representation, and activity. In R. Fivush \& K. Hudson (Eds.), Knowing and remembering in young children (pp. 127-165). New York: Cambridge University Press.

Renninger, K. A. (2000). Individual interest and its implications for understanding intrinsic motivation. In C. Sansone and J. M. Harackiewicz (Eds.), Intrinsic and extrinsic motivation: The search for optimal motivation and performance (pp. 373-404). San Diego, CA: Academic Press, Inc. 
Renninger, K. A., \& Hidi, S. (2011). Revisiting the conceptualization, measurement, and generation of interest. Educational Psychologist, 46, 168-184. https://doi.org/10.1080/00461520.2011.587723

Renninger, K. A., Hidi, S., \& Krapp, A. (1992). The role of interest in learning and development. Hillsdale, NJ: Lawrence Erlbaum.

Renninger, K. A., \& Su, S. (2012). Interest and its development. In R. M. Ryan (Ed.), The Oxford handbook of motivation (pp. 167-187). Oxford: Oxford University.

Rogiers, A., Merchie, E., \& Van Keer H. (2020). Opening the black box of students' text-learning processes: A process mining perspective. Frontline Learning Research. 8(3), 40-62. https://doi.org/10.14786/flr.v8i3.527

Rucker, D. D., Tormala, Z. L., Petty, R. E., \& Briñol, P. (2014). Consumer conviction and commitment: An appraisal-based framework for attitude certainty. Journal of Consumer Psychology, 24(1), 119-136. https://doi.org/10.1016/j.jcps.2013.07.001

Schiefele, U. (1991). Interest, learning, and motivation. Educational Psychologist, 26, 299-323. https://doi.org/10.1080/00461520.1991.9653136

Schiefele, U. (1999). Interest and learning from text. Scientific Studies of Reading, 3, 257-279. https://doi.org/10.1207/s1532799xssr0303_4

Schraw, G., \& Lehman, S. (2001). Situational interest: A review of the literature and directions for future research. Educational Psychology Review, 13, 23-52. https://doi.org/10.1023/A:1009004801455

Silvia, P. J. (2005). What is interesting? Exploring the appraisal structure of interest. Emotion, 5, 89-102. https://doi.org/10.1037/1528-3542.5.1.89

Silvia, P. J. (2006). Exploring the psychology of interest. New York: Oxford University Press.

Silvia, P.J. (2008). Appraisal components and emotion traits: Examining the appraisal basis of trait curiosity. Cognition and Emotion, 22, 94-113. https://doi.org/10.1080/02699930701298481

Simpkins, S. D., Davis-Kean, P. E., \& Eccles, J. S. (2006). Math and science motivation: A longitudinal examination of the links between choices and beliefs. Developmental Psychology, 42, 70-83. https://doi.org/10.1037/0012-1649.42.1.70

Tormala, Z. L. (2016). The role of certainty (and uncertainty) in attitudes and persuasion. Current Opinion in Psychology, 10, 6-11. https://doi.org/10.1016/j.copsyc.2015.10.017

Tormala, Z. L., \& Rucker, D. D. (2007). Attitude certainty: A review of past findings and emerging perspectives. Social and Personality Psychology Compass, 1, 469-492. https://doi.org/10.1111/j.17519004.2007.00025.x

Van Halem, N., van Klaveren, C., Drachsler H., Schmitz, M., \& Cornelisz, I. (2020). Tracking Patterns in Self-Regulated Learning Using Students' Self-Reports and Online Trace Data. Frontline Learning Research. 8 (3) 140-163. https://doi.org/10.14786/flr.v8i3.497

Wijnia, L., Loyens, S. M. M., Derous, E., \& Schmidt, H. G. (2014). Do students' topic interest and tutors' instructional style matter in problem-based learning? Journal of Educational Psychology, 106, 919933. https://doi.org/10.1037/a0037119 